\title{
First approach of characterization of bioactive compound in Pyropia orbicularis during the daily tidal cycle
}

\author{
Nicolás Latorre ${ }^{1,2,3,4}$, Francisco Castañeda ${ }^{1,3}$, Andrés Meynard ${ }^{1,3}$ \\ Jorge Rivas ${ }^{1,3,5}$ \& Loretto Contreras-Porcia ${ }^{1,3,4}$ \\ ${ }^{1}$ Departamento de Ecología y Biodiversidad, Facultad de Ciencias de la Vida \\ Universidad Andres Bello, Santiago, Chile \\ ${ }^{2}$ Programa de Doctorado en Medicina de la Conservación, Facultad de Ciencias de la Vida \\ Universidad Andres Bello, Santiago, Chile \\ ${ }^{3}$ Centro de Investigación Marina Quintay (CIMARQ), Facultad de Ciencias de la Vida \\ Universidad Andres Bello, Quintay, Chile \\ ${ }^{4}$ Center of Applied Ecology \& Sustainability (CAPES), Santiago, Chile \\ ${ }^{5}$ Departamento de Ciencias Químicas, Facultad de Ciencias Exactas \\ Universidad Andres Bello, Santiago, Chile \\ Corresponding author: Loretto Contreras-Porcia (lorettocontreras@unab.cl)
}

\begin{abstract}
The red seaweed Pyropia orbicularis is an economic important species that occurs predominantly in the high intertidal zone along the chilean coast where it experiences extreme conditions under daily turning tides. Its gametophytic phase has been demonstrated to have a high desiccation tolerance, both at the genomic and proteomic levels, but studies at the metabolomic level are still lacking. This research aimed at characterizing compounds related to desiccation stress tolerance by performing several phase solid extractions with different solvents. Bioactivity-guided fractionation (antioxidant and antibacterial activities) was made for a more specific characterization. Compounds identification was done using LC-MS/MS. Results showed that $P$. orbicularis produces different compounds depending on the state of hydration during the tidal cycle. For example, minoxidil was only found under hydration, while vincamine only during desiccation. It was also found that the main antioxidant activity was most likely due to lutein and the antibacterial activity could be mainly attributed to compounds of lipid nature such as phosphatidylethanolamine (PE), phosphatidylserine (PS) and monogalactosyldiacylglycerol (MGDG). These results help to get a better understanding of the stress tolerance mechanisms in $P$. orbicularis and place it like a potential source of bioactive compounds.
\end{abstract}

Keywords: Pyropia orbicularis; oxidative stress; bioactive compounds; stress tolerance; antibacterial activity; antioxidant activity

\section{INTRODUCTION}

The abiotic and biotic gradients factors along the rocky intertidal zone, such as temperature, light intensity, desiccation, competition and predation among others, make it a highly heterogeneous environment (Stephenson \& Stephenson, 1949; Davison \& Pearson, 1996). The organisms inhabiting the intertidal present diverse mechanisms of stress tolerance depending of the distribution zone (high, middle, low or rocky walls) or small scale microenvironments (Davison \& Pearson, 1996; Flores-Molina et al., 2014; Meynard et al., 2019; Zapata et al., 2019). Organisms, under constant environmental pressures, generate an overproduction of reactive oxygen species (ROS), such as superoxide ion $\left(\mathrm{O}^{2-}\right)$, hydrogen peroxide $\left(\mathrm{H}_{2} \mathrm{O}_{2}\right)$ or hydroperoxides (ROOH) among others (Ray et al., 2012), which in turn can cause oxidative damage to important biomolecules (membrane lipids, nucleic acids and proteins) (Mittler, 2002). Tolerance to this oxidative condition triggered

Corresponding editor: Sergio Palma 
by environmental factors, such as temperature, salinity, air exposure and $\mathrm{pH}$, is mainly related to antioxidant enzymatic activity (Foyer et al., 1997; Schafer \& Buettner, 2001; Lovazzano et al., 2013; Hancock, 2017), and compounds (e.g., pyridoxic acid, ascorbic acid, carotenoids, polysaccharides, phycobiliproteins, and peptides) which are involved in lowering the overall levels of cellular ROS (Zhao et al., 2006; Zhang et al., 2009; Yabuta et al., 2010; Isaka et al., 2015; Cian et al., 2016). Some of these compounds are also important in scavenging ROS during stress induced by salinity (Kumar et al., 2010), temperature (Strimbeck et al., 2015) and UV radiation (Zhang et al., 2018). In addition, seaweeds are subjected to a constant biotic pressure, mainly during high tide, with a complex interaction with its diverse epibiota community guided by metabolite and chemical communication (Dobretsov et al., 2009; Egan et al., 2013).

Among representatives of the order Bangiales (Rhodophyta) along the South Pacific coast, Guillemin et al. (2016) established that the red alga Pyropia orbicularis (Ramírez et al., 2014) is distributed between $32^{\circ} \mathrm{S}$ and $53^{\circ} \mathrm{S}$ in the upper rocky intertidal with seasonal variations of its abundance (Betancourtt et al., 2018). Under air exposure during low tide, the gametophytic phase (i.e., macroscopic laminar phase) of $P$. orbicularis can lose up to $96 \%$ of its relative water content and remains dried for up to six hours being able to return to its morphological and metabolic basal condition in less than two hours after being rehydrated (Contreras-Porcia et al., 2011). Desiccation tolerance of $P$. orbicularis has been described at genomic and proteomic levels. It has been determined, that during the first four hours of natural air exposure this species presents changes in the expression of genes involved in cellular respiration, cell wall metabolism, antioxidant activity, synthesis and degradation of proteins and dismantling of photosystems, showing a rapid recovery to the basal states during rehydration (Contreras-Porcia et al., 2013; Fierro et al., 2017). Additionally, it has been documented that under desiccation an increase in the synthesis of proteins linked to energy production occur such as the enzyme triose phosphate isomerase and aconitines; along with down regulation of actin and an upregulation of cofilin/actin depolymerizing factor 3 and phycobiliproteins, all related to cell wall structure preservation or chemical tolerance to oxidative stress triggered by air exposure (López-Cristoffanini et al., 2015). The activation of these tolerance mechanisms would be modulated by the accumulation of the phytohormone abscisic acid (ABA), which act by promoting changes in the metabolism of carbohydrates and in the synthesis and degradation of proteins related to photosynthesis (Guajardo et al., 2016), such as has been determined in vascular plants (Larkindale \& Kinght, 2002; Agarwal et al., 2005). Therefore, the presence of this compound is essential within the mechanisms of tolerance to desiccation, as demonstrated in sensitive species when adding exogenous ABA (Contreras-Porcia et al., 2012).

Tolerance to desiccation can be modulated by both primary and secondary metabolites. This has been documented both in vascular plants and algae (Kumar et al., 2011; Suguiyama et al., 2014; Guajardo et al., 2016). Indeed, the roles of secondary metabolites overlap with definitions of bioactive compounds; for example, "secondary metabolites, which modulate one or more metabolic process, eliciting pharmacological or toxicological effects in humans and animals" (Guaadaoui et al., 2014). In the case of stress due to desiccation, it has been shown that sugars are a fundamental part of tolerance mechanisms in plants (Peters et al., 2007; Toldi et al., 2009), as are also amino acids, organic acids, carbohydrates and fatty acids (Suguiyama et al., 2014). These compounds act physiologically and morphologically, as protective metabolites of the cell membrane (Peters et al., 2007), in the regulation of gas exchange (Nunes-Nesi et al., 2007), as well as antioxidant compounds (Jaiswal et al., 2011). In the red seaweed Pyropia haitanensis the accumulation of floridosides and other volatile compounds such as 3-octanone, 1-octanol was observed under desiccation which would be fulfilling the function of stabilizers of the cell wall (Qian et al., 2015).

Some compounds which would not only play an important role in environmental stress tolerance, but also may act as bioactive compounds and be beneficial for human consumption. For example, fucoxanthin, dimethylsultonipropionate have been described in Fucus vesiculosus as antibacterials (Saha et al., 2011; Svensson et al., 2013); and porphyrans and other polysaccharides have been characterized as antioxidant compounds in species of the genera Porphyra and Pyropia (Zhang et al., 2003; Zhao et al., 2006; Isaka et al., 2015). Recently, the presence of polyphenols, flavonoids and anthraquinones has also been demonstrated, which would have an antioxidant and anti-cancer activity in the seaweeds Desmarestia ligulata, Dictyota kunthii, Chondracanthus chamissoi and Laurencia chilensis (Miranda et al., 2018). In this context, our purpose was to identify compounds associated to desiccation stress tolerance mechanisms, but also those having a potential role as bioactive compounds under desiccation. Therefore, the aims of the present study were i) to identify compounds related to desiccation stress tolerance in the gametophytic phase of $P$. orbicularis and given its economic 
importance ii) to evaluate its potential source of bioactive compounds having antibacterial and antioxidant activities.

\section{MATERIALS AND METHODS}

\begin{abstract}
Algal samples
Pyropia orbicularis gametophytes were collected randomly along a $200 \mathrm{~m}$ long transect perpendicular to the coast from the intertidal zone of Maitencillo, Chile $\left(31^{\circ} 29^{\prime} \mathrm{S}, 71^{\circ} 26^{\prime} \mathrm{W}\right)$. Algae were collected in two tide conditions: at high tide, referred as naturally hydrated $(\mathrm{NH})$, and at low tide during four hours, referred as naturally desiccated (ND). The algae were washed either with filtered seawater $(0.22 \mu \mathrm{m})$ or de-ionized water $(18.2 \mathrm{M} \Omega-\mathrm{cm})$ for the metabolite and bioassay extraction respectively, and a random mix from different individuals for each condition was separated in $1 \mathrm{~g}$ (for the metabolomic analysis) and $25 \mathrm{~g}$ packages (for the bioactivity-guided fractionation). Finally, samples were frozen in situ with liquid nitrogen. For the in vitro experiments, a part of naturally hydrated algae was transported in seawater at $4-7^{\circ} \mathrm{C}$, acclimated overnight at $12-14^{\circ} \mathrm{C}$ in filtered seawater $(\mathrm{H})$ and washed accordingly to the different extraction procedures. Half of these samples were frozen with liquid nitrogen and the other half were subjected to desiccation stress (D), which was done during 4 hours as described by Contreras-Porcia et al. (2011). All the biomass was maintained at $-20^{\circ} \mathrm{C}$ until its extraction.
\end{abstract}

\section{Reagents}

HPLC grade acetone, acetonitrile, dichloromethane, ethanol, n-hexane, methanol and ammonium acetate were purchased from Merck (Merck KGaA, Darmstadt, Germany). Ammonium acetate, ammonium formate, kanamycin and ascorbic acid were purchased from Sigma Aldrich (Merck KGaA, Darmstadt, Germany). The n-heptane, chloro-form, ammonium hydroxide, and 1,1-diphenyl-2-picrylhydrazyl (DPPH) were purchased from Merck (Merck KGaA, Darmstadt, Germany).

\section{Metabolomic characterization \\ Metabolites extraction procedure}

Samples from in situ experiment was grounded in a mortar with liquid nitrogen and $1 \mathrm{~g}$ of powder was extracted with $5 \mathrm{~mL}$ of either de-ionized water, acetonitrile, ethanol or $\mathrm{n}$-hexane. The mixture was agitated using an orbital shaker at $4^{\circ} \mathrm{C}$ for $4 \mathrm{~h}$, and then centrifuged at $1790 \mathrm{~g}$ and $4^{\circ} \mathrm{C}$ for $40 \mathrm{~min}$. The extracts were filtered with a syringe filter of $0.22 \mu \mathrm{m}$ and kept in an amber vial at $4^{\circ} \mathrm{C}$ until chromatographic analysis.

\section{Metabolites chromatographic analysis}

The samples were analyzed by liquid chromatography/tandem mass spectrometry (LC-MS/MS) with electrospray (ESI) as ionization method in an Agilent 1100 HPLC system (Agilent Technologies Inc., CAUSA) coupled to tandem mass spectrometry system with electrospray-triple quadrupole (ESI-QqQ) Esquire 4000 ESI-IT model (Bruker Daltonik GmbH, Germany) both in negative and positive ion mode by spray voltage of $3 \mathrm{kV}$; heated capillary temperature was maintained at $365^{\circ} \mathrm{C}$ with nitrogen as drying gas at 45 psi and $10 \mathrm{~L} \mathrm{~min}^{-1}$. Chromatographic separation was carried out in a C-18 column Inertsil ODS-3 $250 \times 4.6$ $\mathrm{mm}$ with $5 \mu \mathrm{m}$ size particle (GL Sciences Inc., USA) at $30^{\circ} \mathrm{C}$; previously, samples were filtered with a syringe filter at $0.22 \mu \mathrm{m}$ and $20 \mu \mathrm{L}$ were injected in a LCMS/MS. The mobile phase used consisted in a gradient of $0.1 \% \mathrm{~m} / \mathrm{v}$ ammonium acetate in de-ionized water (A) and $0.1 \% \mathrm{~m} / \mathrm{v}$ ammonium acetate in acetonitrile (B) at a constant flow of $0.6 \mathrm{~mL} \mathrm{~min}^{-1}$ (Table 1a), and running time of $45 \mathrm{~min}$. Compounds were identified using the softwares Mass++ (Tanaka et al., 2014) and the databases MassBank (Horai et al., 2010), MassBase (http://webs2.kazusa.or.jp/massbase/), MetaboSearch (Zhou et al., 2012), and BinBase (http://finehnlab. undavis.edu/db).

\section{Bioactivity characterization Bioassay extraction procedure}

Samples of in situ and in vitro experiments were grounded, separately, in a mortar with liquid nitrogen and $20 \mathrm{~g}$ was treated under solid phase extraction with a Soxhlet extraction system (Isolab Laborgeräte $\mathrm{GmbH}$, Germany) during three hours with $200 \mathrm{~mL}$ of either methanol, acetone, dichloromethane or n-hexane, in different batches to establish the greatest bioactivity. The extracts were concentrated in a rotary evaporator (RE-300, Stuart) at $30^{\circ} \mathrm{C}$, and kept at $-20^{\circ} \mathrm{C}$.

\section{Fractionation of bioactive extract with the greatest activity}

The n-hexane extract, showing the greatest bioactivity (see next section), was fractionated in a preparative silica gel (Silica G-60, Dynamic Adsorbent) open

Table 1. HPLC gradient elution programs.

\begin{tabular}{lcccccc}
\hline \multicolumn{3}{c}{$\begin{array}{c}\text { a) Gradient elution for } \\
\text { metabolomic analysis }\end{array}$} & & \multicolumn{3}{c}{$\begin{array}{c}\text { b) Gradient elution for } \\
\text { bioactivities analysis }\end{array}$} \\
\cline { 1 - 2 } \cline { 5 - 7 } $\begin{array}{l}\text { Time } \\
\text { (Min) }\end{array}$ & $\begin{array}{c}\text { Phase A } \\
(\% \mathrm{~V} / \mathrm{V})\end{array}$ & $\begin{array}{c}\text { Phase } \mathrm{B} \\
(\% \mathrm{~V} / \mathrm{V})\end{array}$ & & $\begin{array}{c}\text { Time } \\
(\text { Min })\end{array}$ & $\begin{array}{c}\text { Phase A } \\
(\% \mathrm{~V} / \mathrm{V})\end{array}$ & $\begin{array}{c}\text { Phase B } \\
(\% \mathrm{~V} / \mathrm{V})\end{array}$ \\
\hline 0 & 100 & 0 & & 0 & 5 & 95 \\
10 & 50 & 50 & & 5 & 3 & 97 \\
20 & 25 & 75 & & 10 & 3 & 97 \\
30 & 25 & 75 & & 10.01 & 0 & 100 \\
42 & 0 & 100 & & 58 & 0 & 100 \\
45 & 100 & 0 & & 60 & 5 & 95 \\
\hline
\end{tabular}


column chromatography as described by Vieira et al. (2017), with some modifications. Briefly, $1 \mathrm{~mL}$ of extract was transferred to the n-hexane equilibrated column, and eluted with 2, 10, 20, 30 and $100 \%$ acetone to obtain the fractions $1,2,3,4$ and 5 , respectively. The fractions were evaporated at $30^{\circ} \mathrm{C}$ in a rotary evaporator, resuspended in $500 \mu \mathrm{L}$ methanol and kept at $-20^{\circ} \mathrm{C}$.

\section{Antioxidant assay}

The antioxidant activity was measured with DPPH assay by thin layer chromatography (TLC). $50 \mu \mathrm{g}$ of each extract was spotted onto $20 \times 20 \mathrm{~cm}$ TLC plates (Merck KGaA, Darmstadt, Germany), and were developed with the mobile phase water:ethanol: chloroform:heptane:ammonium hydroxide (2:7:1:1:1). $50 \mu \mathrm{g}$ of the fractions of $n$-hexane extracts (showing the greatest bioactivity) were spotted onto $6 \times 4 \mathrm{~cm}$ TLC plates (Dynamic Adsorbent, silica Gel 60 F254) and were developed with the mobile phase hexane:acetone (7:3). The plates were sprayed with a methanolic solution of $0.2 \%$ of DPPH and the antioxidant activity was quantified by Sorbfil TLC densitometry (v.2.5 JSC SorbPolymer). To compare antioxidant activity (TLCDPPH) of each extract ascorbic acid was used as positive control.

\section{Antibacterial assay}

The antibacterial activity was measured by agar diskdiffusion assay. $100 \mu \mathrm{L}$ of Escherichia coli, Bacillus cereus and Staphylococcus aureus cultures were inoculated $\left(\mathrm{OD}_{600}=0.5\right)$ in $10 \mathrm{~mm}$ Petri dishes with Mueller-Hinton agar and incubated overnight at $37^{\circ} \mathrm{C}$. For each bacterial culture, sterile sensidisks were impregnated with $50 \mu \mathrm{g}$ of each extract or fraction which were placed onto the surface of the agar, using $30 \mu \mathrm{g}$ of Kanamycin (Sigma Aldrich, Merck KGaA, Darmstadt, Germany) as a positive control (Boyle et al., 1973).

\section{Compounds identification}

The bioactive fractions were separated using LCMS/MS (see Chromatographic analysis section) in a C18 column Inertsil ODS $-3250 \times 4.6 \mathrm{~mm}$ with $5 \mu \mathrm{m}$ size particle at $30^{\circ} \mathrm{C}$. Previously, samples were filtered with a syringe filter at $0.22 \mu \mathrm{m}$ and $20 \mu \mathrm{L}$ were injected in a LC-MS/MS. The mobile phase used consisted in a gradient of $10 \mathrm{mmol} \mathrm{L}^{-1}$ ammonium formate in deionized water (A) and $10 \mathrm{mmol} \mathrm{L}^{-1}$ ammonium formate in methanol (B) at a constant flow of $1.5 \mathrm{~mL} \mathrm{~min}{ }^{-1}$ (Table 1b), and running time of $60 \mathrm{~min}$. Compounds were identified using the software Mass++, OpenMS (Pfeuffer et al., 2017), MS-Dial (Tsugawa et al., 2015) and LipidXplorer (Herzog et al., 2013) and the databases MassBank, and LipidBlast (Kind et al., 2013).

\section{Statistical analysis}

For statistical comparisons between compounds identified under NH and ND we performed the following analyses. To describe in multivariate space and search for differences of the metabolomic profile between extraction capacity of the several solvents, we performed a principal coordinate analysis (PCoA) with a similarity index of Bray-Curtis, without differentiating between NH and ND. Since PCoA showed that metabolomic profiles were different between solvents, we performed a permutational ANOVA (Permanova) with a similarity index of Bray-Curtis and 9999 permutations, for each solvent to detect differences between $\mathrm{NH}$ and ND. To compare the relative concentration of each compound between $\mathrm{NH}$ and ND, an ANOVA was applied. It is worth mentioning that since endogenous acetil-CoA signal intensity did not show statistical differences between treatments or solvents, it was used as reference parameter to determinate the other compounds relative concentrations. Then we considered that the relative concentration is the signal area of the compound obtained with the MS in relation with the signal area obtained by acetyl-CoA. The overexpression and inhibition percentage of relative concentration for each compound under ND was categorized in comparison to $\mathrm{NH}$ treatment. After the compound identification, these were categorized into different groups depending on their biological function. For all compounds clustered under each group, significant differences in the relative concentration of compounds under ND (using NH as reference) were assessed applying an ANOVA followed by the post-hoc Tukey multiple comparison test. For the statistical comparison between treatments and solvents in relation to their antioxidant (or antibacterial) bioactivities, we performed a one-way ANOVA, followed by a post-hoc Tukey HSD tests to determine the solvent or treatment presenting the highest bioactivities. Once we defined that $\mathrm{n}$-hexane (and the hydration treatments, $\mathrm{H}$ or $\mathrm{NH}$ ) presented the highest (antioxidant/antibacterial) bioactivities, we performed a one-way ANOVA (fraction as factor), followed by a post-hoc Tukey HSD test to determine the fraction showing the highest bioactivity (for each antioxidant, or antibacterial bioactivity assay, considered independently). All differences were considered statistically significant at a $P<0.05$. Prior to the statistical analyses, data were checked for normality and homogeneity of variances using Shapiro-Wilk and Levene's tests, respectively. We carried out all the extraction, fractionation and bioactivities experiments 
considering three replicates for all the treatments. All statistical analyses were done using PAST software v.3.01 (Hammer et al., 2001), R Core Team (2017).

\section{RESULTS}

\section{General metabolome analysis}

Principal coordinate analysis (PCoA) showed that metabolomic profiles of Pyropia orbicularis were different between the solvents utilized for the compound's separation (Fig. 1). The first coordinate, which corresponds to the used solvents, explains $27 \%$ of data variation, and the second coordinate, which corresponds to $\mathrm{NH}$ (naturally hydration) and ND (naturally desiccation) treatments, explains $25 \%$ of the data variation (52\% in total). The PERMANOVA revealed a significant difference between $\mathrm{NH}$ and ND for all solvents, except $\mathrm{n}$-hexane [de-ionized water $(P=$ $0.013)$, acetonitrile $(P=0.0362)$, methanol $(P=$ $0.0213)$, ethanol $(P=0.024)$ an n-hexane $(P=0.0597)]$

(Fig. 2). Throughout the LC-MS/MS analysis, a total of 30 signals were detected among all the extracts, 15 being observed in both treatments. 4 out of 19 and 10 out of 25 compounds were exclusively observed in $\mathrm{NH}$ and ND, respectively. From the total of the signals, we were able to identify 11 compounds according the

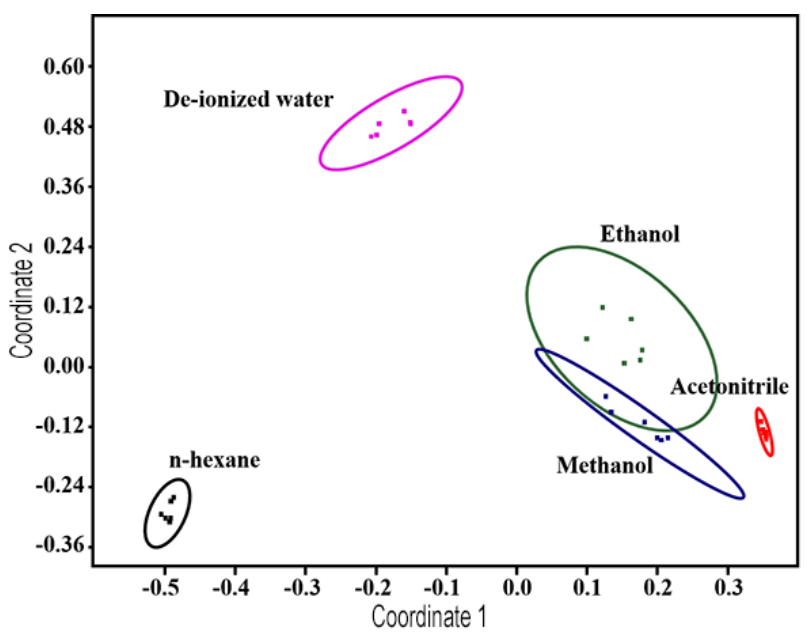

Figure 1. Principal coordinate analysis (PCoA) showed that metabolomic profiles of Pyropia orbicularis were different between solvents utilized.
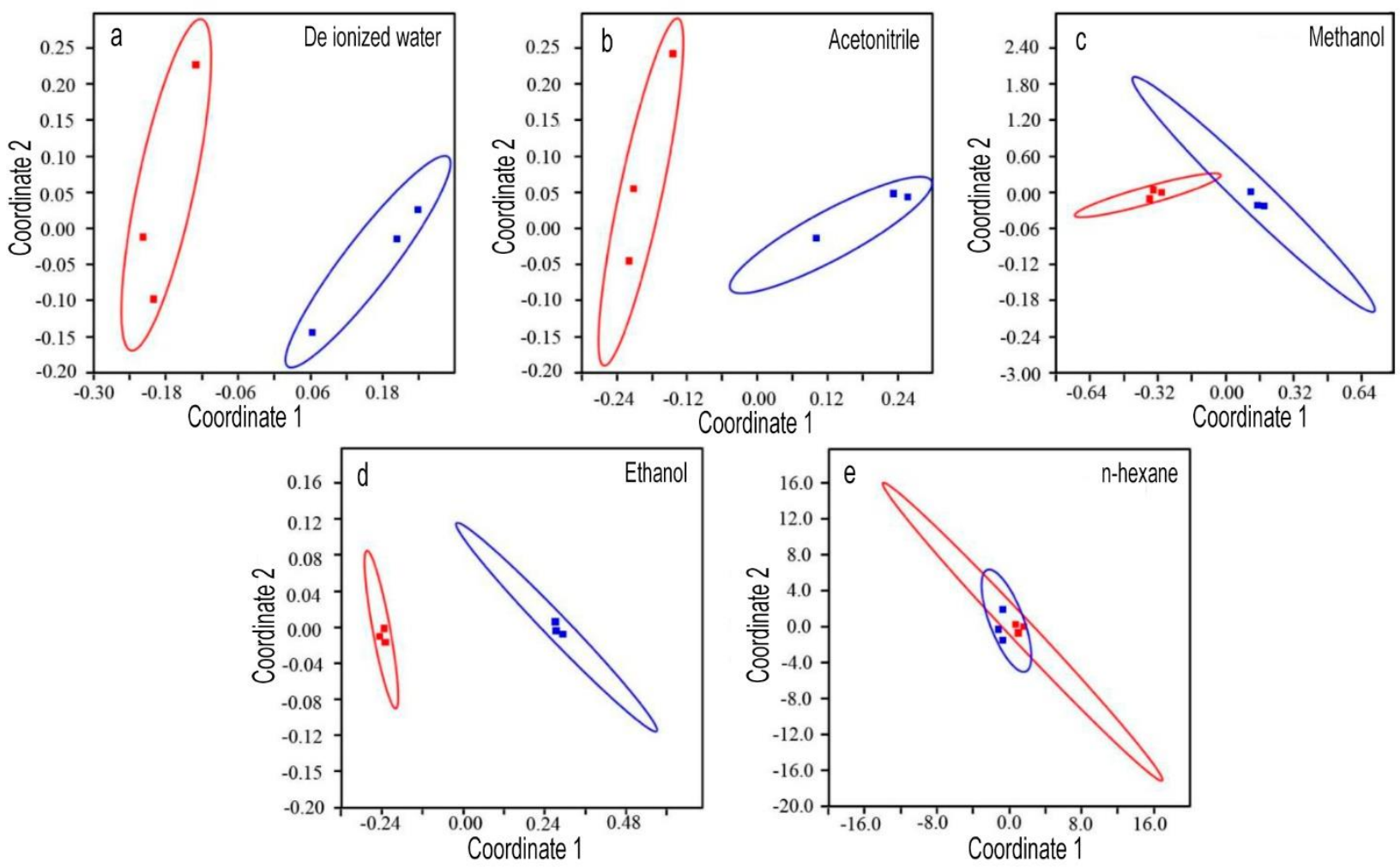

Figure 2. Principal coordinate analyses between naturally hydrated (blue) and naturally desiccated (red) for each extraction solvent: a) de-ionized water, b) acetonitrile, c) methanol, d) ethanol or e) n-hexane. 
Table 2. List of compounds identified with LC-ESI/MS-MS extracted with all solvents. The overexpression (mean increase rate of relative concentration \pm standard deviation) and inhibition percentage of relative concentration for each compound under ND was categorized in comparison to NH treatment. The significant differences of the relative concentrations between ND and NH were established with $P<0.05$ (ANOVA). *Represents the absence of significance differences. The numbers above the name of the compound represent de solvent used in the extraction: deionized water ${ }^{1}$, methanol $^{2}$, acetonitrile ${ }^{3}$. References make mention of previous descriptions of the main function of each compound in other organisms. NH: natural hydration, ND: natural desiccation.

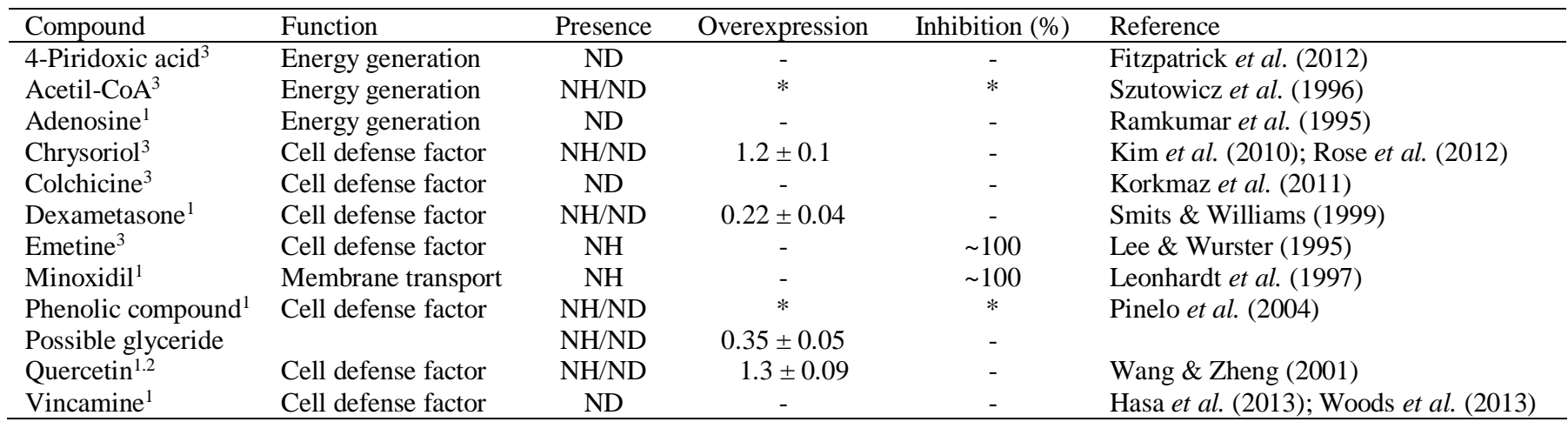

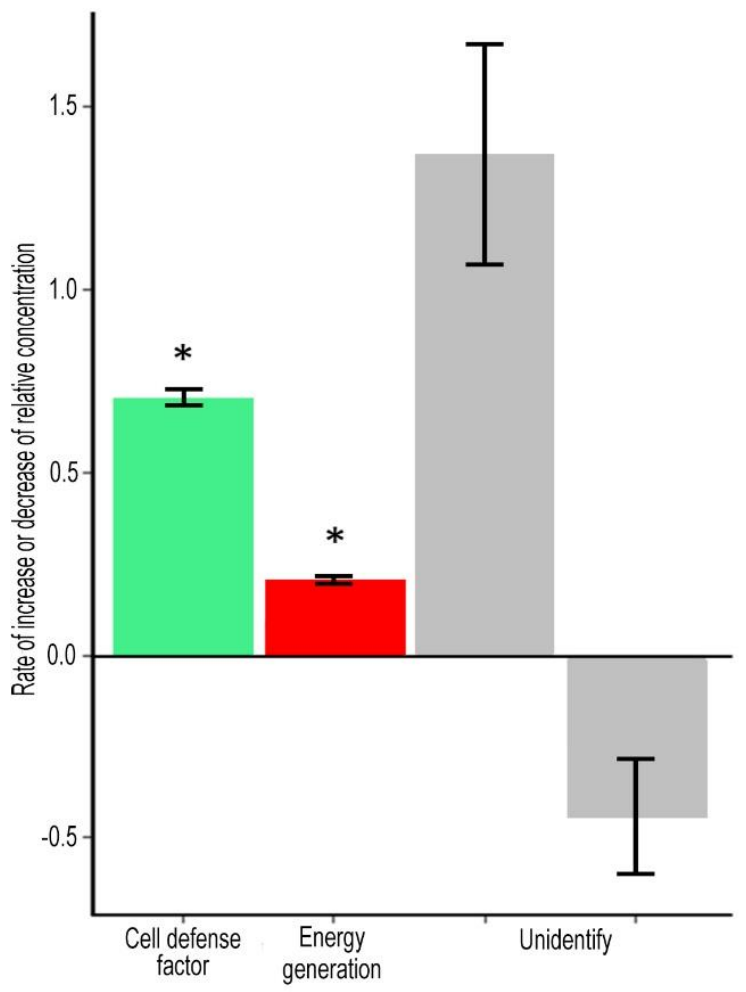

Figure 3. Rate of overexpression (or inhibition) in the concentration (mean $\pm \mathrm{SD}$ ) of compounds belonging to each biological function group (cell defense factor, energy generation or unidentified) under naturally desiccated $(\mathrm{ND})$ in relation to naturally hydrated $(\mathrm{NH})$. Asterisks $(*)$ correspond to statistically significant differences $(P<$ 0.05 ) between $\mathrm{ND}$ and $\mathrm{NH}$ within biological function group (CDF or EG), unidentified compounds not being included in the statistical analysis. Error bars represent (plus/minus) one standard deviation from the mean. databases using MS spectrum data: 4-piridoxic acid, acetil-CoA, chrysoriol, colchicine, dexamethasone, emetine, minoxidil, phenolic compound, a glyceride, quercetin and vincamine. In some cases, a decrease or increase in the relative concentration of these compounds was observed (Table 2). Several signals could not be interpreted since they lacked good resolution in terms of the second ionization from mass spectrum and some of those unidentified compounds could be new since no correspondences were found in the databases.

The identified compounds were separated into three groups depending on their biological function: cell defense factor (CDF), energy generation (EG) and membrane transport (MT) (Table 2). The group with the highest number of compounds identified was the cell defense factor, $62.5 \%$ in NH and $70 \%$ in ND. Then comes the group of energy generation, with $25 \%$ in $\mathrm{NH}$ and $30 \%$ in ND. The MT group was only observed in the NH treatment and was only composed by minoxidil. The average relative concentration of the CDF group was 0.7 times higher in ND than in NH, and the EG group was 0.2 times higher in ND than in NH. It should be noted that for the unidentified compounds groups, most compounds increased (1.3 times) under ND (Fig. 3).

\section{Bioactive analysis}

The antioxidant activity of crude extracts from Pyropia orbicularis was maintained among all the conditions studied. An increased and statistically significant activity was found in n-hexane extracts in comparison to extracts using other solvents (Fig. 4), but no differen- 

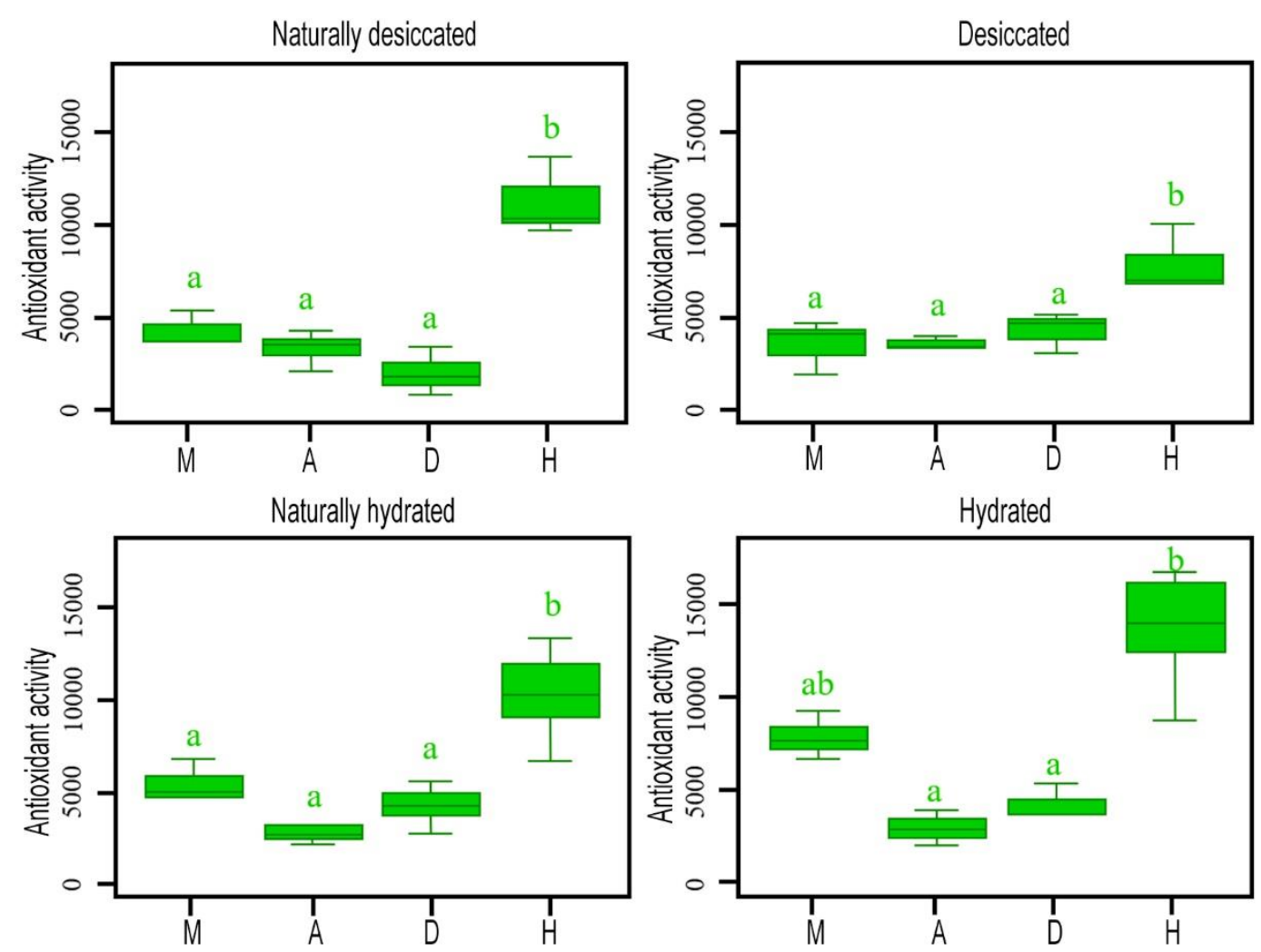

Figure 4. Boxplots of antioxidant activity (median, and lower and upper whiskers) of crude extracts of Pyropia orbicularis with different solvents [M: methanol, A: acetone, D: dichloromethane and $\mathrm{H}$ : $\mathrm{n}$-hexane] under the conditions of natural desiccation, in vitro desiccation, natural hydration and in vitro hydration. The antioxidant activity was measured by the direct assay TLC-DPPH with ascorbic acid used as a positive control. For each treatment considered independently, levels not connected by the same letter ( $\mathrm{a}$ or b) correspond to solvents showing significantly different bioactivities (antioxidant activity) based on post-hoc Tukey HSD analysis with $P<0.05$.

ces was observed under hydration $(\mathrm{H}$ or $\mathrm{NH})$ and desiccation (D or ND) treatments. This was also observed in the antibacterial assay, where the highest bacterial inhibition was obtained from n-hexane extract against Bacillus cereus (Fig. 5), particularly under the natural treatments (ND and $\mathrm{NH}$ ) in comparison to the in vitro conditions (H and D) (Fig. 5).

Since both antibacterial and antioxidant capacities showed a higher activity in n-hexane extracts, these extracts were chosen for fractioning and identification (see methodology). The highest inhibition against Bacillus cereus and Escherichia coli was observed in the fraction 4 from n-hexane extract, which was comparable to the activity of kanamycin (Fig. 6). Low antibacterial activities (inhibition halos) for all fractions were evidenced in Staphylococcus aureus.

Since the main antioxidant fraction from $P$. orbicularis carried a bright yellow color, it was most likely a carotenoid compound. Then, a HPLC-UV method was developed to further separate the compounds of each fraction. In fact, with a purified fraction of carotenoids from Haematococcus pluvialis using as control (Sun et al., 2015), we were able to determine the presence of lutein at retention time $9.42 \mathrm{~min}$ in the fraction 4 of $P$. orbicularis (Table 3 ).

To identify the compounds responsible for the antibacterial activity, each bioactive fraction (3, 4 and 5) was submitted to LC-ESI/MS-MS and analyzed using the software MS-DIAL. The signals that appeared on all the chromatograms were identified using the databases available in MassBank and LipidBlast. These analyses allowed determining the presence of monogalactosyldiacylglycerol (MGDG), lysophosphatidylcholine (LPC), phosphatidylserine (PS) and diacylglycerols (DAG). In order to quantify the abundance of different lipid classes within each fraction, and to identify the possible source of antibacterial activity, the LipidXplorer software was subsequently used. The lipid classes PC-O (phosphatidylcholineether), PE (phosphatidylethanolamine), PS (phosphatidylserine), PI (phosphatidylinositol), GlCer (glucosylceramide), TAG (triacylglycerols) and SM 

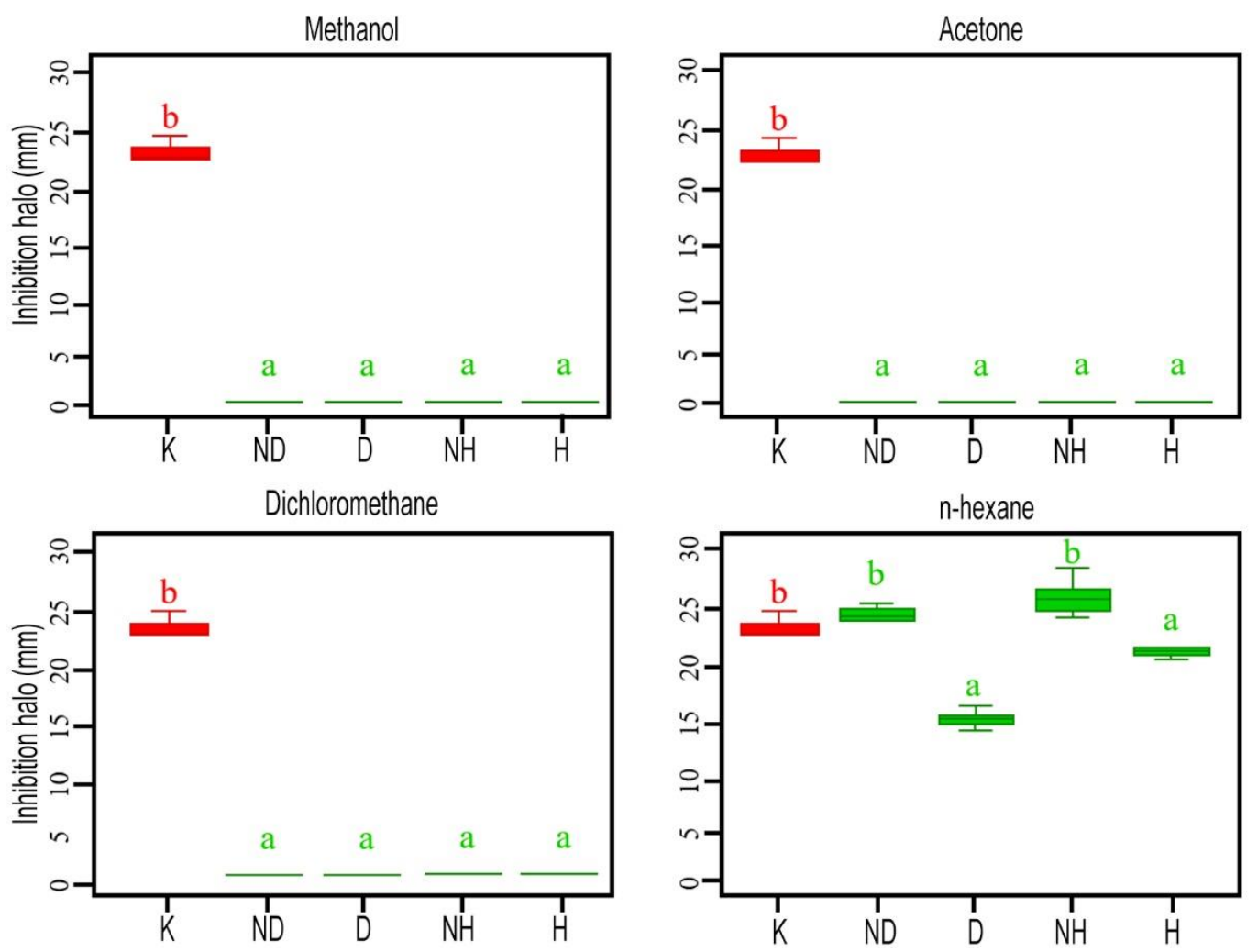

Figure 5. Boxplots of antibacterial activity (median, and lower and upper whiskers) against Bacillus cereus of crude extracts of Pyropia orbicularis with different solvents (methanol, acetone, dichloromethane and n-hexane) under the conditions of natural desiccation (ND), desiccation (D), natural hydration $(\mathrm{NH})$ and hydration $(\mathrm{H})$ with kanamycin $(\mathrm{K})$ as a positive control. For each solvent considered independently, levels not connected by the same letter a or b correspond to treatments showing significantly different bioactivities (inhibition halos) based on post-hoc Tukey HSD analysis with $P<0.05$.

(sphingomyelin) were more abundant in all the fractions that showed high antibacterial activity; while PE-O (phosphatidylethanolamineether), DAG (diacylglycerols), LPC (lysophosphatidylcholine) and LPE (lysophosphatidylethanolamine) presented higher concentrations in fractions with low bioactivity (Fig. 7).

\section{DISCUSSION}

\section{General metabolome analysis}

In accordance with previous studies of ContrerasPorcia et al. (2013); López-Cristoffanini et al. (2015) and Fierro et al. (2017) at the genomic and proteomics levels in Pyropia orbicularis, our results show a differential metabolomic response in natural desiccation (ND) in comparison to natural hydration (NH). This differential response has been extensively studied in resurrection plants, for which several compounds have been identified (Moore et al., 2009; Yobi et al., 2012; Gechev et al., 2013; Suguiyama et al., 2014). Few studies have been published on this subject in the
Table 3. Carotenoid retention time. Carotenoid extraction from different species, this data was used to prove the presence of lutein in Pyropia orbicularis. Porphyra CHF corresponds to a Chilean genetic species identified by Guillemin et al. (2016).

\begin{tabular}{llc}
\hline Species & Carotenoid & $\begin{array}{c}\text { Retenton time } \\
\text { (min) }\end{array}$ \\
\hline Heamatococcus & Lutein & 9.4 \\
pluvialis & Astaxanthin & 6.1 \\
& Astaxanthin monoester & 29.4 \\
& Astaxanthin monoester & 30.2 \\
Pyropia orbicularis & Lutein & 9.4 \\
Agarophyton chilensis & Lutein & 9.4 \\
Porphyra CHF & Lutein & 9.4 \\
\hline
\end{tabular}

Bangiales, for example Qian et al. (2014) showed that in $P$. haitanensis, a rapid accumulation of volatile compounds and floridosides is observed under ND. The compounds identified in our study, during NH and ND, fulfill diverse functions. The 4-piridoxic acid is a participant in the biosynthesis of vitamin B6, having an active role as a cellular defense factor against oxidative 

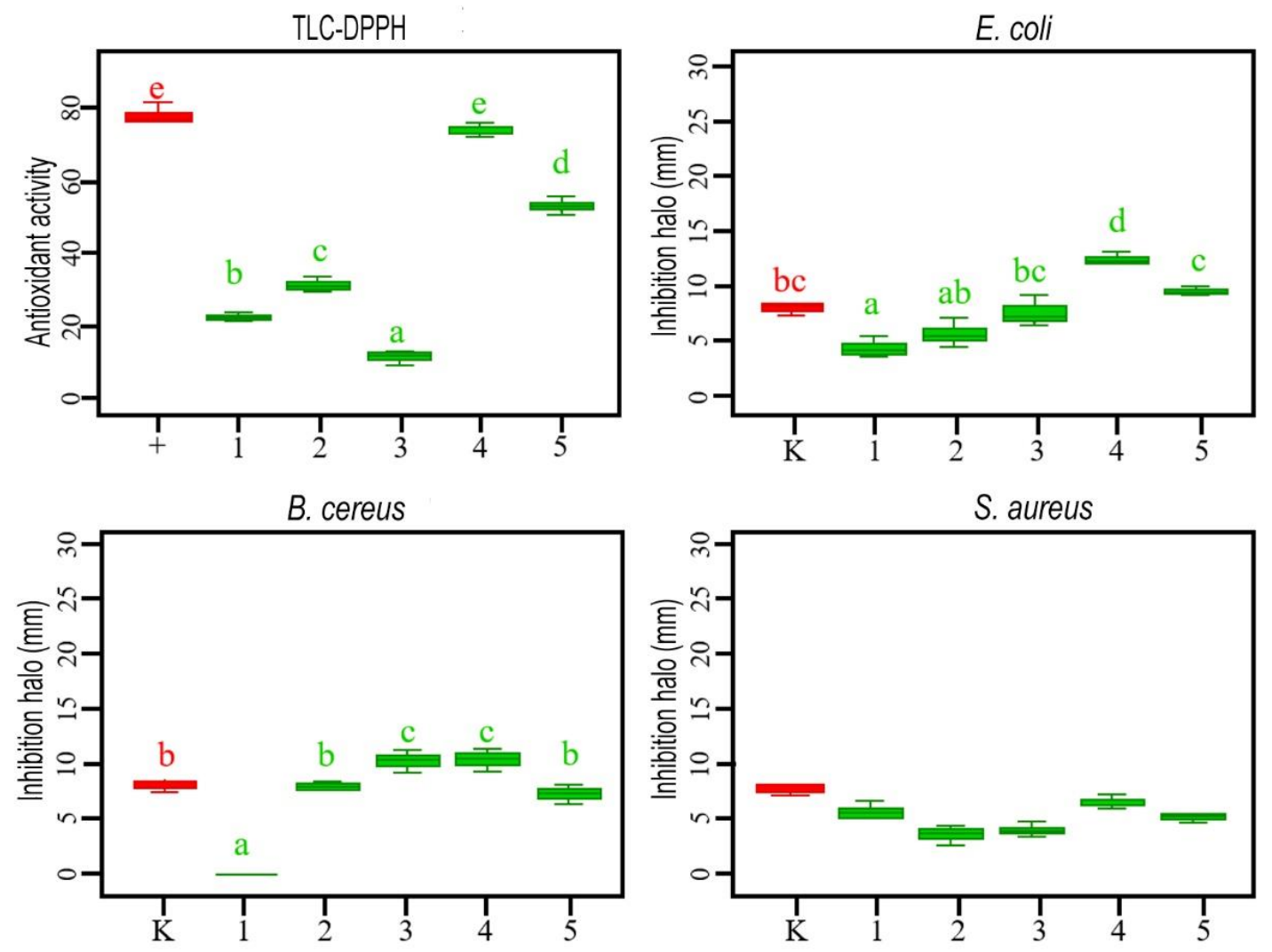

Figure 6. Boxplots of bioactivities (median, and upper and lower whiskers) of the fractions (1-5) from the hexane extract of natural hydration Pyropia orbicularis. Antioxidant activity was measured by TLC-DPPH and represented as DPPH inhibition (\%) with ascorbic acid (+) as a positive control. Antibacterial activity against Escherichia coli, Bacillus cereus and Staphylococcus aureus with Kanamycin (K) as a positive control. For each (antioxidant, or antibacterial) bioactivity essay, considered independently, levels not connected by the same letter correspond to fractions showing significantly different activities based on post-hoc Tukey HSD analysis with $P<0.05$.

stress (Havaux et al., 2009). It is also used as a cofactor for enzymes involved in metabolic pathways of fatty acids and glucose (Fitzpatrick et al., 2012). We suggest that 4-piridoxic acid was identified only in ND because in this condition $P$. orbicularis uses more energy than in $\mathrm{NH}$ in order to induce the synthesis of desiccation stress tolerance compounds and proteins as described by López-Cristoffanini et al. (2015). Like 4-pyridoxic acid, adenosine is involved in biochemicals processes such as energy transfer and has been shown to act as an endogenous promoter of the antioxidant cellular defense system (Maggirwar et al., 1994; Ramkumar et al., 1995). Chrysoeriol has multiples functions such as UV cell protection in plants, antioxidant activity and induction of the transcription of nod genes in Rhizobium meliloti, a symbiotic bacterium of legume plants (Hartwig et al., 1990; Kim et al., 2010). The overexpression of this compound in ND may be related to its antioxidant activity and its UV protection capacity, since $P$. orbicularis is exposed directly to sunlight at low tide. Colchicine inhibits cellular division with reported antioxidant and antiinflammatory activity (Korkmaz et al., 2011) and it was detected only in ND. Quercetin, which has antioxidant properties (Jullian et al., 2007) but most importantly modulates growth, development and cell death in plants (Wang \& Zheng, 2001), showed a greater relative concentration in ND than in NH. Then, both colchicine and quercetin could be regulating the growth of $P$. orbicularis directly or indirectly and acting as a ROS scavenger in the ND condition. The alkaloid, emetine, has antiprotozoal and antioxidant activity (Lee \& Wurster, 1995). This compound was only identified in $\mathrm{NH}$, so it could be acting like antiprotozoal in high tide, since in high tide $P$. orbicularis may be exposed to a higher microbial load, as previously mentioned. Emetine is also part of the release of mRNA, from stress granules, involved in the synthesis of proteins playing a pivotal role in environmental stress tolerance in human cell lines (HeLa) (Kedersha et al., 2000, 2005). 


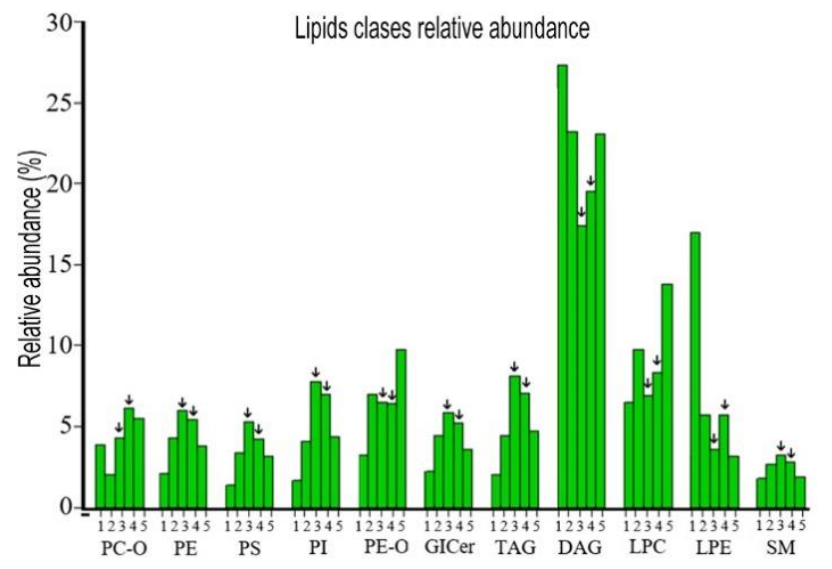

Figure 7. Lipid classes relative abundance identified in the fractions (1-5) from the hexane extract of natural hydration Pyropia orbicularis. Lipid classes Phosphatidylcholineether (PC-O), Phosphatidylethanolamine (PE), Phosphatidylserine (PS), Phosphatidylinositol (PI), Phosphatidylethanolamineether (PE-O), Glucosylceramide (GlCer), Triacylglycerols (TAG), Diacylglycerols (DAG), Lysophosphatidylcholine (LPC), Lysophosphatidylethanolamine (LPE) and Sphingomyelin (SM) were identified by LipidXplorer. Arrows indicate fractions 3 and 4 which showed the highest antibacterial activities.

Nonetheless, the presence of stress granules in seaweeds has not been proven, which is why we propose more studies in this area. Vincamine is an alkaloid with antioxidant properties (Woods et al., 2013) which may be part of the ROSs scavenger mechanisms in the ND condition. Dexamethasone has anti-inflammatory functions and is an immunosuppressor in birds (Smits \& Williams, 1999), but there are no reported activity in plants or algae related with oxidative stress tolerance. The other compounds in the list are not included in this description because they do not have a relevant function related to oxidative stress tolerance or an exact identification of them is not still available. For those unidentified compounds, more exhaustive and specific extractions, and other characterization analyses such gas chromatography-MS (GCMS) and nuclear magnetic resonance (NMR) are needed to identify them. Nevertheless, unidentified compounds showing higher average concentration under ND than NH could play an important role in environmental stress tolerance. This statement is based on previous studies showing that, in both plants and algae, most compounds increasing their concentration under stress conditions are related to tolerance mechanisms (Whittaker et al., 2001; Suguiyama et al., 2014; Chen et al., 2016). Then, we found compounds in NH and ND probably corresponding to constitutive responses; whereas, other compounds were exclusively presents in ND may indicate an induced response.
On the other hand, some of these compounds could be classified as antioxidant com-pounds while others may be classified as bioactive compounds, i.e., eliciting pharmacological or toxicolo-gical effects.

\section{Bioactive analysis}

The (antioxidant and antibacterial) bioactivities observed in this study showed no major differences under desiccation in comparison to hydration in $P$. orbicularis, suggesting that there is no induction of antibacterial or antioxidant compounds through the daily tidal cycle. This alga would then show a constitutive response. Since antibacterial activity was highest under the natural desiccation than the in vitro treatments, other abiotic conditions should be considered, such as temperature or light intensity to fully understand the trigger of this activity. For example, the synthesis of antibacterial compound zinc oxide by the angiosperm Hibiscus subdariffa (Malvales order) has been shown to be dependent on temperature (Bala et al., 2015)

In relation to the main antioxidant capacities, within Rhodophyta, Bangiophycae can produce both lutein and zeaxanthin (Takaichi et al., 2016) and there are reports of their presence in Porphyra and Pyropia spp. (Schubert et al., 2006; Oh et al., 2013). In agreement with that, in our study, we identified lutein in $P$. orbicularis. However, there were no significant differences in the antioxidant activities observed from the n-hexane extracts under the ND and NH treatments suggesting that the lutein content would not be affected by this factor. This is in accordance with previous studies (Wu, 2016) where, for example, there was no differences in the modulation of the carotenoid levels in Pyropia haitanensis cultivated under different light intensities, despite observing differences in the concentration of other photosynthetic pigments such as chlorophyll- $a$, phycoerythrin and phycocyanin.

PE and PS lipids extracted from seaweeds have been previously linked to antibacterial activity against gram positive and negative bacteria (Abd \& Baky, 2014). It has been documented that under natural desiccation Laurencia snackeyi would not be degraded by microorganisms, most likely due to MGDG antibacterial activity, unlike during in vitro desiccation (Vairappan, 2003). Our results showed that desiccation alone does not seem to induce exclusively the antibacterial activity found in Pyropia orbicularis, suggesting that it should remain throughout the tidal cycle. The antibacterial activity found in this study was not attributed to a single compound, and it is most likely due to lipids and its derivatives, or at least to nonpolar compounds. Indeed, it has been previously reported that different seaweed present a highest antibacterial 
activity from the nonpolar fraction in comparison to the polar one, suggesting that lipid classes might be involved (Kamenarska et al., 2009; Abd \& Baky, 2014). In fact, lipids may decay on derivative compounds such as the biologically active oxylipins (Mosblech et al., 2009) and there are reports of prostaglandins obtained from Gracilaria spp. which may cause food-poisoning (Fusetani \& Hashimoto, 1984; Imbs et al., 2012) and serve as chemical defense against epiphytes (Weinberger et al., 2011).

\section{CONCLUSIONS}

Our study demonstrates that stress tolerance during the tidal cycle in Pyropia orbicularis, at the metabolomic level, is not only modulated by antioxidant compounds, but rather by a variety of other compounds. Among these other compounds, we found some showing pharmacological effects (beneficial effects in human health) and other eliciting toxicological (antibacterial) effects. Our results suggest that the lipid fraction fulfills an important antioxidant and antibacterial role. It would be necessary to further characterize the lipid fraction involved in the oxidative stress defense mechanisms. This result helps to understand the environmental stress tolerance in seaweed in the intertidal zone and to propose $P$. orbicularis as a potential source of bioactive compounds.

\section{ACKNOWLEDGEMENT}

This research was funded by FONDECYT 1120117 and 1170881.

\section{REFERENCES}

Abd, H.H. \& Baky, E. 2014. Cytotoxicity, antioxidants and antimicrobial activities of lipids extracted from some marine algae development production of bioactive substances from microalgae for functional foods view project algae as the third generation biofuel: production, usage challenges and prospects view project. Journal of Aquaculture Research and Development, 5: $7 \mathrm{pp}$.

Agarwal, S., Sairam, R.K., Srivastava, G.C., Tyagi, A. \& Meena, R.C. 2005. Role of ABA, salicylic acid, calcium and hydrogen peroxide on antioxidant enzymes induction in wheat seedlings. Plant Science, 169(3): 559-570.

Bala, N., Saha, S., Chakraborty, M., Maiti, M., Das, S., Basu, R. \& Nandy, P. 2015. Green synthesis of zinc oxide nanoparticles using Hibiscus subdariffa leaf extract: effect of temperature on synthesis, anti- bacterial activity and anti-diabetic activity. RSC Advances, 5(7): 4993-5003.

Betancourtt, C., Zapata, J., Latorre, N., Anguita, C., Castañeda, F., Meynard, A., Fierro, C., Espinoza, C., Guajardo, E., Núñez, A., Salas, N., González, C., Ramírez, M.E., Bulboa-Contador, C. \& ContrerasPorcia, L. 2018. Spatio-temporal variation in the composition of the macroalgae assemblage of the intertidal rocky zone from Maitencillo, Valparaíso, central coast of Chile. Revista de Biología Marina y Oceanografía, 53(1): 105-117.

Boyle, V.J., Fancher, M.E. \& Ross, R.W. 1973. Rapid modified Kirby-Bauer susceptibility test with single, high-concentration antimicrobial disks. Antimicrobial Agents and Chemotherapy, 3(3): 418-424.

Chen, J., Li, M., Yang, R., Luo, R., Xu, J., Ye, Y. \& Yan, X. 2016. Profiling lipidome changes of Pyropia haitanensis in short-term response to high-temperature stress. Journal of Applied Phycology, 28(3): 19031913.

Cian, R.E., Garzón, A.G., Ancona, D.B, Guerrero, L.C. \& Drago, S.R. 2016. Chelating properties of peptides from red seaweed Pyropia columbina and its effect on iron bio-accessibility. Plant Foods for Human Nutrition, 71(1): 96-101.

Contreras-Porcia, L., Thomas D., Flores, V. \& Correa, J.A. 2011. Tolerance to oxidative stress induced by desiccation in Porphyra columbina (Bangiales, Rhodophyta). Journal of Experimental Botany, 62(6): 1815-1829.

Contreras-Porcia, L., Callejas, S., Thomas, D., Sordet, C., Pohnert, G., Contreras, A., Lafuente, A., FloresMolina, M.R. \& Correa, J.A. 2012. Seaweeds early development: detrimental effects of desiccation and attenuation by algal extracts. Planta, 235(2): 337-348.

Contreras-Porcia, L., Lopez-Cristoffanini, C., Lovazzano, C., Flores-Molina, M.R., Thomas, D., Nuñez, A., Fierro, C., Guajardo, E., Correa, J.A., Kube, M. \& Reinhardt, R. 2013. Differential gene expression in Pyropia columbina (Bangiales, Rhodophyta) under natural hydration and desiccation conditions. Latin American Journal of Aquatic Research, 41(5): 933958.

Davison, I.R. \& Pearson, G.A. 1996. Stress tolerance in intertidal seaweeds. Journal of Phycology, 32(2): 197211.

Dobretsov, S., Teplitski, M. \& Paul, V. 2009. Minireview: quorum sensing in the marine environment and its relationship to biofouling. Biofouling, 25(5): 413-427.

Egan, S., Harder, T., Burke, C., Steinberg, P., Kjelleberg, S. \& Thomas, T. 2013. The seaweed holobiont: understanding seaweed-bacteria interactions. FEMS Microbiology Reviews, 37(3): 462-476. 
Fierro, C., López-Cristoffanini, C., Meynard, A., Lovazzano, C., Castañeda, F., Guajardo, E. \& Contreras-Porcia, L. 2017. Expression profile of desiccation tolerance factors in intertidal seaweed species during the tidal cycle. Planta, 245(6): 11491164.

Fitzpatrick, T.B., Basset, G.J.C., Borel, P., Carrari, F., DellaPenna, D., Fraser, P.D., Hellmann, H., Osorio, S., Rothan, C., Valpuesta, V., Caris-Veyrat, C. \& Fernie A.R. 2012. Vitamin deficiencies in humans: can plant science help? The Plant Cell, 24(2): 395-414.

Flores-Molina, M.R., Thomas, D., Lovazzano, C., Núñez, A., Zapata, J., Kumar, M., Correa, J.A. \& ContrerasPorcia, L. 2014. Desiccation stress in intertidal seaweeds: effects on morphology, antioxidant responses and photosynthetic performance. Aquatic Botany, 113: 90-99.

Foyer, C.H., Lopez-Delgado, H., Dat, J.F. \& Scott, I.M. 1997. Hydrogen peroxide- and glutathione-associated mechanisms of acclimatory stress tolerance and signalling. Physiologia Plantarum, 100(2): 241-254.

Fusetani, N. \& Hashimoto, K. 1984. Prostaglandin E2: A candidate for causative agent of 'Ogonori' poisoning. Bulletin of the Japanese Society of Scientific Fisheries, 50(3): 465-469.

Gechev, T.S., Benina, M., Obata, T., Tohge, T., Sujeeth, N., Minkov, I., Hille, J., Temanni, M.R., Marriott, A.S., Bergstöm, E., Thomas-Oates, J., Antonio, C., Muller-Roeber, B., Schippers, J.H.M., Fernie, A.R. \& Toneva, V. 2013. Molecular mechanisms of desiccation tolerance in the resurrection glacial relic Haberlea rhodopensis. Cellular and Molecular Life Sciences, 70(4): 689-709.

Guaadaoui, A., Benaicha, S., Elmajdoub, N., Bellaoui, M. \& Hamal, A. 2014. What is a bioactive compound? A combined definition for a preliminary consensus. International Journal of Nutrition and Food Sciences, 3(3): 174-179.

Guajardo, E., Correa, J.A. \& Contreras-Porcia, L. 2016. Role of abscisic acid (ABA) in activating antioxidant tolerance responses to desiccation stress in intertidal seaweed species. Planta, 243(3): 767-781.

Guillemin, M.L., Contreras-Porcia, L., Ramírez, M.E., Macaya, E.C., Bulboa, C., Woods, H., Wyatt, C. \& Brodie, J. 2016. The bladed Bangiales (Rhodophyta) of the South Eastern Pacific: molecular species delimitation reveals extensive diversity. Molecular Phylogenetics and Evolution, 94: 814-826.

Hammer, O., Harper, D.A.T. \& Ryan, P.D. 2001. PAST: paleontological statistics software package for education and data analysis. Palaeontologia Electronica, 4: 19.

Hancock, R.D. 2017. Oxidative stress. In: Encyclopedia of applied plant sciences. Academic Press, Orlando, pp. 27-35.
Hartwig, U.A., Maxwell, C.A., Joseph, C.M. \& Phillips, D.A. 1990. Chrysoeriol and luteolin released from alfalfa seeds induce nod genes in Rhizobium meliloti. Plant Physiology, 92(1): 116-122.

Hasa, D., Perissutti, B., Grassi, M., Chierotti, M.R., Gobetto, R., Ferrario, V., Lenaz, D. \& Voinovich, D. 2013. Mechanochemical activation of vincamine mediated by linear polymers: assessment of some "critical" steps. European Journal of Pharmaceutical Sciences, 50(1): 56-68.

Havaux, M., Ksas, B., Szewczyk, A., Rumeau, D., Franck, F., Caffarri, S. \& Triantaphylidès, C. 2009. Vitamin B6 deficient plants display increased sensitivity to high light and photo-oxidative stress. BMC Plant Biology, 9: 1-22.

Herzog, R., Schwudke, D. \& Shevchenko, A. 2013. LipidXplorer: Software for quantitative shotgun lipidomics compatible with multiple mass spectrometry platforms. Current Protocols in Bioinformatics, 43(1): 12-14.

Horai, H., Arita, M., Kanaya, S., Nihei, Y., Ikeda, T., Suwa, K., Ojima, Y. et al. 2010. MassBank: a public repository for sharing mass spectral data for life sciences. Journal of Mass Spectrometry, 45(7): 703714.

Imbs, A.B., Latyshev, N.A., Svetashev, V.I., Skriptsova, A.V., Le, T.T., Pham, M.Q., Nguyen, V.S. \& Pham, L.Q. 2012. Distribution of polyunsaturated fatty acids in red algae of the genus Gracilaria, a promising source of prostaglandins. Russian Journal of Marine Biology, 38(4): 339-345.

Isaka, S., Cho, K., Nakazono, S., Abu, R., Ueno, M., Kim, D. \& Oda, T. 2015. Antioxidant and anti-inflammatory activities of porphyran isolated from discolored nori (Porphyra yezoensis). International Journal of Biological Macromolecules, 74: 68-75.

Jaiswal, R., Kiprotich, J. \& Kuhnert, N. 2011. Determination of the hydroxycinnamate profile of 12 members of the Asteraceae family. Phytochemistry, 72(8): 781-790.

Jullian, C., Moyano, L., Yañez, C. \& Olea-Azar, C. 2007. Complexation of quercetin with three kinds of cyclodextrins: an antioxidant study. Spectrochimica Acta Part A, 67(1): 230-234.

Kamenarska, Z., Serkedjieva, J., Najdenski, H., Stefanov, K., Tsvetkova, I., Dimitrova-Konaklieva, S. \& Popov, S. 2009. Antibacterial, antiviral, and cytotoxic activities of some red and brown seaweeds from the Black Sea. Botanica Marina, 52(1): 80-86.

Kedersha, N., Cho, M.R., Li, W., Yacono, P.Q., Chen, S., Gilks, N., Golan, D.E. \& Anderson, P. 2000. Dynamic shuttling of TIA-1 accompanies the recruitment of 
mRNA to mammalian stress granules. Journal of Cell Biology, 151(6): 1257-1268.

Kedersha, N., Stoecklin, G., Ayodele, M., Yacono, P., Lykke-Andersen, J., Fitzler, M.J., Scheuner, D., Kaufman, R.K., Golan, D.E. \& Anderson, P. 2005. Stress granules and processing bodies are dynamically linked sites of mRNP remodeling. Journal of Cell Biology, 169(6): 871-884.

Kim, Y.H., Lee, Y.S. \& Choi, E.M. 2010. Chrysoeriol isolated from Eurya cilliata leaves protects MC3T3E1 cells against hydrogen peroxide-induced inhibition of osteoblastic differentiation. Journal of Applied Toxicology, 30(7): 666-673.

Kind, T., Liu, K.H., Lee, D.Y., Defelice, B., Meissen, J.K. \& Fiehn, O. 2013. LipidBlast in silico tandem mass spectrometry database for lipid identification. Nature Methods, 10(8): 755-758.

Korkmaz, S., Erturan, Í., Nazıroğlu, M., Uğuz, A.C., Çiğ, B. \& Övey, İ.S. 2011. Colchicine modulates oxidative stress in serum and neutrophil of patients with behçet disease through regulation of $\mathrm{Ca}^{2+}$ release and antioxidant system. Journal of Membrane Biology, 244(3): 113-120.

Kumar, M., Kumari, P., Gupta, V., Reddy, C.R.K. \& Jha, B. 2010. Biochemical responses of red alga Gracilaria corticata (Gracilariales, Rhodophyta) to salinity induced oxidative stress. Journal of Experimental Marine Biology and Ecology, 391(1-2): 27-34.

Kumar, M., Gupta, V., Trivedi, N., Kumari, P., Bijo, A.J., Reddy, C.R.K. \& Jha, B. 2011. Desiccation induced oxidative stress and its biochemical responses in intertidal red alga Gracilaria corticata (Gracilariales, Rhodophyta). Environmental and Experimental Botany, 72(2): 194-201.

Larkindale, J. \& Knight, M.R. 2002. Protection against heat stress-induced oxidative damage in Arabidopsis involves calcium, abscisic acid, ethylene, and salicylic acid. Plant Physiology, 128(2): 682-695.

Lee, Y.S. \& Wurster, R.D. 1995. Effects of antioxidants on the anti-proliferation induced by protein synthesis inhibitors in human brain tumor cells. Cancer Letters, 93(2): 157-163.

Leonhardt, N., Marin, E., Vavasseur, A. \& Forestier, C. 1997. Evidence for the existence of a sulfonylureareceptor-like protein in plants: modulation of stomatal movements and guard cell potassium channels by sulfonylureas and potassium channel openers. Proceedings of the National Academy of Sciences of the United States of America, 94(25): 14156-14161.

López-Cristoffanini, C., Zapata, J., Gaillard, F., Potin, P., Correa, J.A. \& Contreras-Porcia, L. 2015. Identification of proteins involved in desiccation tolerance in the red seaweed Pyropia orbicularis (Rhodophyta, Bangiales). Proteomics, 15(23-24): 3954-3968.
Lovazzano, C., Serrano, C., Correa, J.A. \& ContrerasPorcia, L. 2013. Comparative analysis of peroxiredoxin activation in the brown macroalgae Scytosiphon gracilis and Lessonia nigrescens (Phaeophyceae) under copper stress. Physiology Plantarum, 149(3): 378-388.

Maggirwar, S.B., Dhanraj, D.N., Somani, S.M. \& Ramkumar, V. 1994. Adenosine acts as an endogenous activator of the cellular antioxidant defense system. Biochemical and Biophysical Research Communications, 201(2): 508-515.

Meynard, A., Zapata, J., Salas, N., Betancourtt, C., PérezLara, G., Castañeda, F., Ramírez, M.E., BulboaContador, C., Guillemin, M.L. \& Contreras-Porcia, L. 2019. Genetic and morphological differentiation of Porphyra and Pyropia species (Bangiales, Rhodophyta) coexisting in a rocky intertidal in Central Chile. Journal of Phycology, 55(2): 297-313.

Miranda, A., Montoya, M., Araos, M., Mellado, M., Villena, J., Arancibia, P., Madrid, A. \& Jara, C. 2018. Antioxidant and anticancer activities of brown and red seaweed extracts from Chilean coasts. Latin American Journal of Aquatic Research, 46(2): 301-313.

Mittler, R. 2002. Oxidative stress, antioxidants and stress tolerance. Trends in Plant Science, 7(9): 405-410.

Moore, J.P., Le, N.T., Brandt, W.F., Briouich, A. \& Farrant, J.M. 2009. Towards a systems-based understanding of plant desiccation tolerance. Trends in Plant Science, 14(2): 110-117.

Mosblech, A., Feussner, I. \& Heilmann, I. 2009. Oxylipins: structurally diverse metabolites from fatty acid oxidation. Plant Physiology and Biochemistry, 47(6): 511-517.

Nunes-Nesi, A., Carrari, F., Gibon, Y., Sulpice, R., Lytovchenko, A., Fisahn, J., Graham, J., Ratcliffe, R.G., Sweetlove, L.J. \& Fernie, A.R. 2007. Deficiency of mitochondrial fumarase activity in tomato plants impairs photosynthesis via an effect on stomatal function. Plant Journal, 50(6): 1093-1106.

Oh, S., Shin, M., Lee, K. \& Choe, E. 2013. Effects of water activity on pigments in dried laver (Porphyra) during storage. Food Science and Biotechnology, 22(6): 1523-1529.

Peters, S., Mundree, S.G., Thomson, J.A., Farrant, J.M. \& Keller, F. 2007. Protection mechanisms in the resurrection plant Xerophyta viscosa (Baker): Both sucrose and raffinose family oligosaccharides (RFOs) accumulate in leaves in response to water deficit. Journal of Experimental Botany, 58(8): 1947-1956.

Pfeuffer, J., Sachsenberg, T., Alka, O., Walzer, M., Fillbrunn, A., Nilse, L., Schilling, O., Reinert, K. \& Kohlbacher, O. 2017. OpenMS - a platform for reproducible analysis of mass spectrometry data. Journal of Biotechnology, 261: 142-148. 
Pinelo, M., Rubilar, M., Sineiro, J. \& Núñez, M.J. 2004. Extraction of antioxidant phenolics from almond hulls (Prunus amygdalus) and pine sawdust (Pinus pinaster). Food Chemistry, 85(2): 267-273.

Qian, F., Luo, Q., Yang, R., Zhu, Z., Chen, H. \& Yan, X. 2015. The littoral red alga Pyropia haitanensis uses rapid accumulation of floridoside as the desiccation acclimation strategy. Journal of Applied Phycology, 27(1): 621-632.

Ramírez, M.E., Contreras-Porcia, L., Guillemin, M.L., Brodie, J., Valdivia, C., Flores-Molina, M.R., Núñez, A., Bulboa-Contador, C. \& Lovazzano, C. 2014. Pyropia orbicularis sp. nov. (Rhodophyta, Bangiaceae) based on a population previously known as Porphyra columbina from the central coast of Chile. Phytotaxa, 158(2): 133-153.

Ramkumar, V., Nie, Z., Rybak, L.P. \& Maggirwar, S.B. 1995. Adenosine, antioxidant enzymes and cytoprotection. Trends in Pharmacologycal Science, 16(9): 283-285.

Ray, P.D., Huang, B.W. \& Tsuji, Y. 2012. Reactive oxygen species (ROS) homeostasis and redox regulation in cellular signaling. Cellular Signaling, 24(5): 981-990.

R Core Team 2017. R: A language and environment for statistical computing. R Foundation for Statistical Computing. [http://www.Rproject.org]. Reviewed: september 10, 2018.

Rose, C.M., Venkateshwaran, M., Volkening, J.D., Grimsrud, A.P., Maeda, J., Bailey, J.D., Park, K., Howes-Podoll, M., Den Os, D., Yeun, L.H., Westphall, M.S., Sussman, M.R., Ané, J.M. \& Coon, J.J. 2012. Rapid phosphoproteomic and transcriptomic changes in the rhizobia-legume symbiosis. Molecular and Cellular Proteomics, 11(9): 724-744.

Saha, M., Rempt, M., Grosser, K., Pohnert, G. \& Weinberger, F. 2011. Surface-associated fucoxanthin mediates settlement of bacterial epiphytes on the rockweed Fucus vesiculosus. Biofouling, 27(4): 423433.

Schafer, F.Q. \& Buettner, G.R. 2001. Redox environment of the cell as viewed through the redox state of the glutathione disulfide/glutathione couple. Free Radical Biology and Medicine, 30(11): 1191-1212.

Schubert, N., García-Mendoza, E. \& Pacheco-Ruiz, I. 2006. Carotenoid composition of marine red algae. Journal of Phycology, 42(6): 1208-1216.

Smits, J.E. \& Williams, T.D. 1999. Validation of immunotoxicology techniques in passerine chicks exposed to oil sands tailings water. Ecotoxicology and Environmental Safety, 44(1): 105-112.
Stephenson, T.A. \& Stephenson, A. 1949. The universal features of zonation between tide-marks on rocky coasts. Journal of Ecology, 37(2): 289.

Strimbeck, G.R., Schaberg, P.G., Fossdal, C.G., Schröder, W.P. \& Kjellsen, T.D. 2015. Extreme low temperature tolerance in woody plants. Frontiers in Plant Science, 6: 884 .

Suguiyama, V.F., Silva, E.A., Meirelles, S.T., Centeno, D.C. \& Braga, M.R. 2014. Leaf metabolite profile of the Brazilian resurrection plant Barbacenia purpurea Hook (Velloziaceae) shows two time-dependent responses during desiccation and recovering. Frontiers in Plant Science, 5: 1-13.

Sun, W., Lin, H., Zhai, Y., Cao, L., Leng, K. \& Xing, L. 2015. Separation, purification, and identification of (3S, 3'S)-trans-Astaxanthin from Haematococcus pluviallis. Separation Science and Technology, 50(9): 1377-1383.

Svensson, J.R., Nylund, G.M., Cervin, G., Toth, G.B. \& Pavia, H. 2013. Novel chemical weapon of an exotic macroalga inhibits recruitment of native competitors in the invaded range. Journal of Ecology, 101(1): 140148.

Szutowicz, A., Tomaszewicz, M. \& Bielarczyk, H. 1996. Disturbances of acetyl-CoA, energy and acetylcholine metabolism in some encephalopathies. Acta Neurobiologiae Experimentalis Journal, 56: 323-340.

Takaichi, S., Yokoyama, A., Mochimaru, M., Uchida, H. \& Murakami, A. 2016. Carotenogenesis diversification in phylogenetic lineages of Rhodophyta. Journal of Phycology, 52(3): 329-338.

Tanaka, S., Fujita, Y., Parry, H.E., Yoshizawa, A.C., Morimoto, K., Murase, M., Yamada, Y. et al. 2014. Mass++: a visualization and analysis tool for mass spectrometry. Journal of Proteome Research, 13(8): 3846-3853.

Toldi, O., Tuba, Z. \& Scott, P. 2009. Vegetative desiccation tolerance: is it a goldmine for bioengineering crops? Plant Science, 176(2): 187-199.

Tsugawa, H., Cajka, T., Kind, T., Ma, Y., Higgins, B., Ikeda, K., Kanazawa, M., Vandergheynst, J., Fiehn, O. \& Arita, M. 2015. MS-DIAL: Data-independent MS/MS deconvolution for comprehensive metabolome analysis. Nature Methods, 12(6): 523-526.

Vairappan, C.S. 2003. Potent antibacterial activity of halogenated metabolites from Malaysian red algae, Laurencia majuscula (Rhodomelaceae, Ceramiales). Biomolecular Engieneering, 20: 255-259.

Vieira, F.A., Guilherme, R.J.R., Neves, M.C., Abreu, H., Rodrigues, E.R.O., Maraschin, M., Coutinho, J.A.P. \& Ventura, S.P.M. 2017. Single-step extraction of 
carotenoids from brown macroalgae using non-ionic surfactants. Separation and Purification Technology, 172: $268-276$.

Wang, S.Y. \& Zheng, W. 2001. Effect of plant growth temperature on antioxidant capacity in strawberry. Journal of Agricultural and Food Chemistry, 49(10): 4977-4982.

Weinberger, F., Lion, U., Delage, L., Kloareg, B., Potin, P., Beltrán, J., Flores, V., Faugeron, S., Correa, J. \& Pohnert, G. 2011. Up-regulation of lipoxygenase, phospholipase, and oxylipin-production in the induced chemical defense of the red alga Gracilaria chilensis against epiphytes. Journal of Chemical Ecology, 37(7): 677-686.

Whittaker, A., Bochicchio, A., Vazzana, C., Lindsey, G., \& Farrant, J. 2001. Changes in leaf hexokinase activity and metabolite levels in response to drying in the desiccation-tolerant species Sporobolus stapfianus and Xerophyta viscosa. Journal of Experimental Botany, 52(358): 961-969.

Woods, J.R., Riofski, M.V., Zheng, M.M., O'Banion, M.A., Mo, H., Kirshner, J. \& Colby, D.A. 2013. Synthesis of 15-methylene-eburnamonine from (+)vincamine, evaluation of anticancer activity, and investigation of mechanism of action by quantitative NMR. Bioorganic \& Medicinal Chemistry Letters, 23(21): 5865-5869.

Wu, H. 2016. Effect of different light qualities on growth, pigment content, chlorophyll fluorescence, and antioxidant enzyme activity in the red alga Pyropia haitanensis (Bangiales, Rhodophyta). BioMed Research International, 2016: 1-8.

Yabuta, Y., Fujimura, H., Kwak, C.S., Enomoto, T. \& Watanabe, F. 2010. Antioxidant activity of the phycoerythrobilin compound formed from a dried korean purple laver (Porphyra sp.) during in vitro digestion. Food Science and Technology Research, 16(4): 347-352.

Received: 1 April 2019; Accepted: 7 October 2019
Yobi, A., Wone, B.W., Xu, W. , Alexander, D.C., Guo, L., Ryals, J.A., Oliver, M.J. \& Cushman, J.C. 2012. Comparative metabolic profiling between desiccationsensitive and desiccation-tolerant species of Selaginella reveals insights into the resurrection trait. Plant Journal, 72(2): 983-999.

Zapata, J., Meynard, A., Anguita, C., Espinoza, C., Alvear, P., Kumar, M. \& Contreras-Porcia, L. 2019. Non-random distribution and ecophysiological differentiation of Pyropia species (Bangiales, Rhodophyta) through environmental gradients. Journal of Phycology, 14 pp. https://doi.org/10.1111/jpy.12900.

Zhang, Q., Li, N., Zhou, G., Lu, X., Xu, Z. \& Li, Z. 2003. In vivo antioxidant activity of polysaccharide fraction from Porphyra haitanesis (Rhodophyta) in aging mice. Pharmacological Research, 48(2): 151-155.

Zhang, X., Ding, X., Ji, Y., Wang, S., Chen, Y., Luo, J., Shen, U. \& Peng, L. 2018. Measurement of metabolite variations and analysis of related gene expression in Chinese liquorice (Glycyrrhiza uralensis) plants under UV-B irradiation. Scientific Reports, 8(1): 6144.

Zhang, Z., Zhang, Q., Wang, J., Zhang, H., Niu, X. \& Li, P. 2009. Preparation of the different derivatives of the low-molecular-weight porphyran from Porphyra haitanensis and their antioxidant activities in vitro. International Journal of Biological Macromolecules, 45(1): 22-26.

Zhao, T., Zhang, Q., Qi, H., Zhang, H., Niu, X., Xu, Z. \& Li, Z. 2006. Degradation of porphyran from Porphyra haitanensis and the antioxidant activities of the degraded porphyrans with different molecular weight. International Journal of Biological Macromolecules, 38(1): 45-50.

Zhou, B., Wang, J. \& Ressom, H.W. 2012. Metabosearch: tool for mass-based metabolite identification using multiple databases. Plos One, 7(6):e40096. 